\title{
A Cognitive Style Based Framework for Usability Evaluation of Online Lecturing Platforms - A Case Study on Zoom and Teams
}

\author{
https://doi.org/10.3991/ijep.v12i1.25295 \\ Heba Ismail ${ }^{1}(\llbracket)$, Adel Khelifi ${ }^{1}$, Saad Harous ${ }^{2}$ \\ ${ }^{1}$ Abu Dhabi University, Abu Dhabi, UAE \\ ${ }^{2}$ University of Sharjah, Sharjah, UAE \\ heba.ismail@adu.ac.ae
}

\begin{abstract}
Recently, Zoom and Microsoft Teams have emerged as the most common tools for lecturing activities in higher education institutions. The fact that these platforms were not originally developed for educational purposes resulted in a significant reduction in learning effectiveness, especially in STEM subjects that require a lot of practical knowledge. Despite the enhancements and updates made to these platforms, they have failed to meet the learning effectiveness criteria. A major hindering to learning effectiveness on such systems can be traced not only to the absence of learning-related features but also to their usability. In this research, we propose a framework for evaluating the usability of online lecturing platforms. The proposed framework introduces a new set of heuristics that are specifically designed for lecturing activities and considers VAK learning styles. Since students with different learning styles learn differently, we developed the first cognitive style-based usability heuristics that can reliably assess the usability of online learning environments for various types of learners. We present a case study that uses the suggested evaluation framework to assess the usability of Zoom and Teams in higher education lecturing activities. The findings of this study, however, can be applied to almost any online lecture platform.
\end{abstract}

Keywords-usability evaluation, heuristics, cognitive styles, e-learning, higher education, online lecturing

\section{Introduction}

The sudden outbreak of COVID-19 has caused schools and colleges around the globe to shift suddenly into online learning. While some educational institutes managed to secure a successful transition, many were not prepared for online learning [1][2]. As a quick resolution, many schools and higher educational institutes relied on Zoom [3], and Microsoft Teams [4], video conferencing tools, to continue offering their lessons and lectures online without major interruption of study.

These platforms have not only made it possible to take lectures online, but they have also made it possible to share learning content, record lectures, engage with 
students through chat or conversation, and use whiteboards for an explanation. Therefore, many schools continued to use these platforms. Despite the many advantages to using blended learning and e-learning in the engineering context [5], [6], Zoom and Microsoft Teams, on the other hand, were not initially designed for online learning. As such, these platforms were not designed for learners or teachers as the primary users, neither were designed for lecturing contexts. As a result, students and educators reported several difficulties during online lectures[1][2][7]. Despite the many enhancements to these platforms that introduced learning-related features, some students continued reporting usage problems and difficulties during lectures, which hindered their engagement and learning. As a result, problems with Teams and Zoom are seen to be not only attributed to the availability of learning-related features, but also to the design and to the usability of these platforms for online lecturing activities. Several usability issues could be impeding the efficacy of these platforms to support online lecturing activities especially for engineering subjects that rely on problem-solving pedagogy. To this end, this study proposes a usability evaluation framework aiming to improve and inform the design of these lecturing platforms supporting the higher efficacy of online engineering education through similar platforms.

Several research works looked at the usability of various e-learning platforms [8], [9], [10]. Several heuristics for evaluating the online learning experience, in general, were suggested in these studies. However, the scope of these studies was often broader than the lecturing experience itself, hence, this study conducts extensive research to develop a suitable set of heuristics for the assessment of the online lecturing activity. Furthermore, since students' cognitive styles differ significantly and affect their interaction modes, including their interactivity during online lectures [11],[12], the proposed heuristics account for these differences. We propose a comprehensive usability evaluation framework for lecturing platforms with the new set of cognitive stylebased heuristics. The proposed framework defines eight phases that can be followed to effectively evaluate any online lecturing platform while considering learners' cognitive styles. Initial evaluation results of the proposed framework were presented in EDUCON21 [13]. This study is an extended and more comprehensive version of the evaluation paper. The following research questions are addressed in this research:

- RQ (1): Do students with different learning styles identify different usability issues in online lecturing platforms?

- RQ (2): Do online lecturing platforms differ in the way they accommodate learners' learning styles?

This paper is organized as follows: first, we introduce a brief literature review related to the usability of online learning environments and cognitive styles, then we explain in detail the components of the prosed usability evaluation framework and we end this paper by presenting a comprehensive analysis and discussion of results. 


\section{Literature review}

\subsection{Heuristic evaluation in e-learning environments}

The process of measuring the usability of a product or device on several levels is known as usability evaluation. Usability Evaluations are not to be confused with usability itself, according to Rosenzweig [14]. Usability Evaluation is the approach that helps us to evaluate this holistic view of the usefulness of the studied object, while Usability encompasses a more holistic view of the usefulness of the studied object. Nielsen's claimed Heuristic Evaluation (HE) is the most well-known and widely used of these techniques in Computer System Interfaces [15]. Nielsen and Molich, the two members of "The Nielsen Norman Group" for User Experience Research, first proposed this form of assessment in 1990 [16]. They recommended that a usable system should "keep users updated about its status," "display details in ways users understand from how the real world works," "allow users to quickly undo errors," "be transparent so users aren't confused," and "avoid situations where errors occur or alert users before they take risky acts". They also stated that a system should " have visible information, instructions, etc. to let users recognize options, actions, etc. instead of forcing them to rely on memory", "be flexible so experienced users find faster ways to attain goals", "have no clutter", "provide plain-language help regarding errors and solutions", and "list concise steps in lean, searchable documentation for overcoming problems" [16].

A small group of experts works separately to test a system and decide whether or not a set of usability principles has been met in its design. Experiments have shown that there is little correlation between problems encountered by various evaluators, so the results of each specialist are compared for optimum effectiveness. Three to five experts, according to Neilson, should be included. This is because, as Figure. 1 shows, combining the findings of multiple evaluators yields better results. It does, however, point out that there is a cost-benefit analysis that shows adding more than five evaluators can only be used in sensitive systems [15]. 


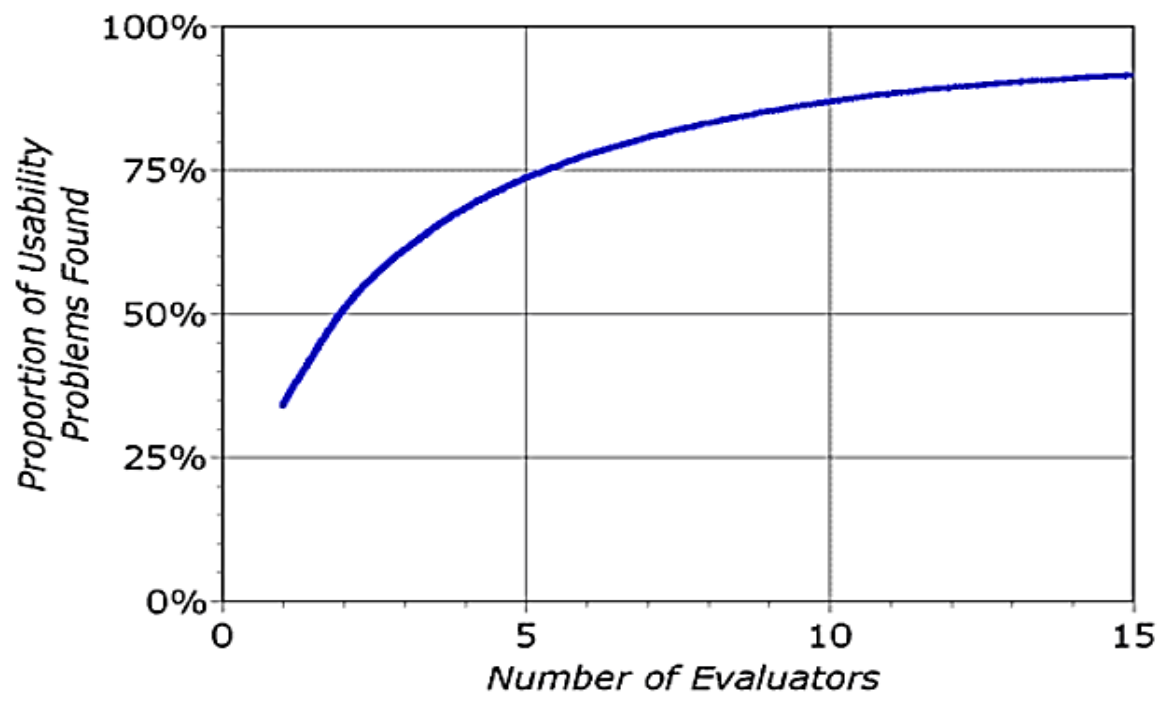

Fig. 1. Usability problems found by heuristic evaluation with various numbers of evaluators as averaged from six case studies[15]

Nielsen refined his and Molich's previous list in 1994, resulting in what is now known as "Nielsen's Heuristics"[15], which are used for heuristic comparison:

1. Visibility of System Status.

2. Match Between System and The Real World.

3. User Control and Freedom.

4. Consistency and Standards.

5. Error Prevention.

6. Recognition Rather Than Recall.

7. Flexibility and Efficiency of Use.

8. Aesthetic and Minimalist Design.

9. Help Users Recognize, Diagnose, And Recover from Errors

10. Help and Documentation.

Although Heuristic Evaluation is commonly used in online learning and other fields of study, not everyone employs the ten points mentioned above. According to Mehlenbacher et al. [8], all instructional circumstances have five dimensions: Learner Background and Knowledge, Learner Tasks and Activities, Social Dynamics, Instructor Activities, and Learning Environment and Tools. They suggested [8] a set of heuristics that can be used to evaluate these dimensions are proposed. Similarly, when it comes to evaluating educational software, heuristic evaluators should include both learners and educational design and content experts, according to Reeves et al. [10]. Quinn also mentions [17] the need to change the heuristics list to include good education elements derived from classic problems in current designs.

Several research ventures, on the other hand, have proposed several changes to conventional heuristics. This is due to their lack of detail when it comes to more spe- 
cific studies. For example, Ssemugabi and De Villiers, the research group with a cognitive psychology faculty member, adapted Nielsen's ten heuristics [9], to incorporate web-based e-learning environment context that increased the number of heuristics to twenty. The researchers wanted to provide a set of heuristics that were more closely related to E-learning and accounts of learning-specific features. Similarly, Albion of the University of Southern Queensland adapted both Neilsen's and Quinn's heuristics and proposed a set of e-learning-related heuristics [18].

Despite other researchers' contributions to adapting Neilson's heuristics to the Elearning context, we find the existing heuristics lacking in terms of users' learning styles and not specific to the lecturing context. Hence, we aim to further narrow the heuristic's scope to concentrate on the "Lecturing" activity of e-learning in this study. We also intend to integrate learning styles into the heuristics to accommodate different types of learners. In the subsequent sections, we introduce the proposed heuristics evaluation framework for online lecturing platforms as well as the proposed heuristics.

\subsection{Learning styles and their relevance to e-learning}

Dunn first proposed the idea of "Learning Style" in 1960 [19], and its meaning can be summarized as the learner's desires. Kazu [11], argued that this can be affected by their gender, context, intelligence level, and other personal characteristics. There are three key components of a Learning Style, according to Cornett [20]. These are:

Cognitive aspects. include a learner's methods for "decode, encode, process, store, and retrieve information". This aspect, according to the professor, distinguishes between similar pairs: focusing vs scanning, randomly vs sequentially, and concretely vs abstractly. A learner usually comes somewhere in between the two extremes but makes use of both.

Affective aspects. are the part of the learning style that deals with the learner's cognitive and personality traits. This has to do with "motivation, attention, locus of control, interests, willingness to take risk, persistence, responsibility, and sociability" according to Cornett. As a result, this is the factor that relates to which reward the learner responds to the most, as well as the type of group in which they work best on a task, for example.

Physiological aspects. the last of the components relates to sensory perception (visual, auditory, kinesthetic, taste, and smell), environmental characteristics (noise level, illumination, temperature, and room arrangement), the need for food when studying, and optimal learning times of the day.

Accordingly, students process and maintain knowledge in several ways. They can learn knowledge in a variety of ways with some effort; however, Pinchot and Paullet [21], stated that most have a greater propensity to understand new concepts if it is conveyed in a particular way. As a result, the three key VAK learning styles were identified as follows:

The visual learning style. This learner likes to see the content and knowledge written or shown in front of them. They learn better by associating details with pictures, numbers, and other visual aids. They memorize long texts by breaking them 
down into color-coded sections, and they often close their eyes and try to recall the layout of a page to recall the details written on it. As a result, it's clear that most traditional teaching techniques, such as personalized text, charts, and graphs, appeal to these learners. Yet, Pinchot and Paullet [21] and Newton [22], explained since these students are easily distracted by sounds and needless imagery, spoken instructions are not a good match for them.

The auditory learning style. This learner absorbs knowledge by listening to others or speaking aloud. They tend to absorb information by sound rather than visual or tactile means, and they often repeat commands to themselves to ensure that they fully comprehend them. The best way to teach these students is to have teachers orally demonstrate how to do something. They ask a lot of questions to help them remember the sound of the idea, and they use their phones to record lessons that they can go back to and listen to later [21], [22].

Kinesthetic (tactile) learning style. These students learn better by doing things for themselves and engaging in physically demanding tasks. They prefer to learn by doing rather than hearing about it or watching someone else do it, and they prefer to be taught by going along with the instructor rather than waiting for them to finish first. They are considered impatient and easily bored learners and interactive practice and assessments are always the best method for their learning [21], [22].

Although other learning models have been established to reflect learners with overlapping types, the VAK three groups remain the most representative and influential [21], [22], and are thus the subjects of this research. Kolb and Kolb [23], showed that learning Styles can be identified and pinpointed for a student to change their learning attitude and increase the efficacy of their efforts. A digital environment is not excluded. Dag and Geçer [24], conducted a systematic literature review on the relationship between cognitive styles and efficacy of online learning and highlighted that a significant increase in research interest in the field of online learning and learning styles after 2001. Furthermore, Zapalska and Brozik [12], noted that auditory type learners were seen to step away from online education due to their preference for hearingbased learning, and recommended that a variety of strategies be used to enable all types of learners to engage and excel in online learning.

On a similar note, Zajac [25], suggested that Learning Styles can be used to go beyond the common personalization of time, location, and visual layout, suggesting a deeper level of personalization where the form of delivery is also tailored to the learner's style, and stressing the greater importance of such an approach to learning. To that end, we suggest that adding a new set of usability heuristics that integrate learning styles would increase the quality of e-learning usability evaluation.

\section{Methods}

As discussed earlier, the aim of this study is to propose a usability evaluation framework and to validate this framework with a case study in higher education to improve the usability of online lecturing platforms and hence improve learning efficacy. To accomplish these objectives, a framework consisting of eight major design 
evaluation tasks is proposed. These tasks are explained in subsequent sections and illustrated in Figure 2.

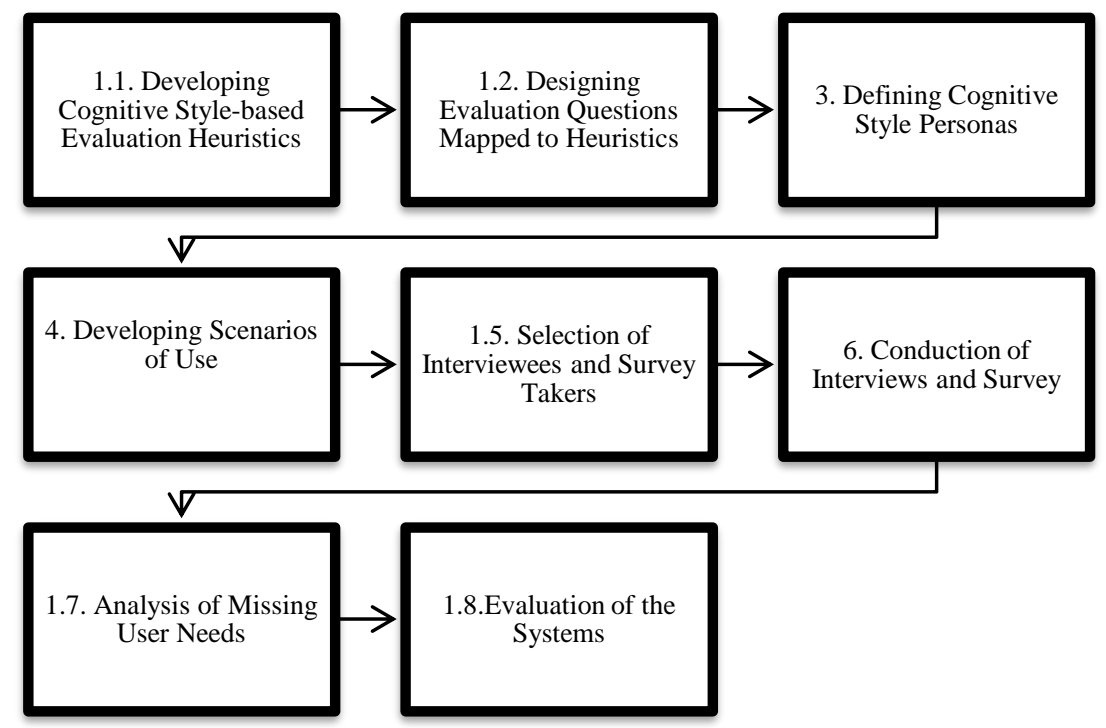

Fig. 2. Proposed lecturing platform usability evaluation framework

\subsection{Phase -1-: Developing cognitive style-based evaluation heuristics}

Initially and before starting any usability evaluation, a relevant and representative set of evaluation criteria need to be established. In the proposed framework, cognitive style-based heuristics evaluation criteria are proposed. Several studies focused on the usability evaluation of different e-learning platforms and proposed several heuristics [8], [9], [10]. However, the reported heuristics do not incorporate learning styles. Hence, we propose two new categories of heuristics to evaluate the usability of online lecturing environments as follows:

Category 1: User interaction usability criteria. We adapt the set of ten usability heuristics developed by Jacob Nielsen [16], to the lecturing activity context. Table 1 illustrates a possible set of e-lecturing interactivity heuristics which can be further extended based on the system's attributes and features.

Table 1. Category -1- Heuristics - user interaction usability criteria

\begin{tabular}{|l|l|}
\hline Num & \multicolumn{1}{|c|}{ Heuristic Name and Description } \\
\hline 1 & $\begin{array}{l}\text { Visibility of the Lecturing Platform's Status } \\
\text { The lecturing platform keeps the learners informed about what is going on with the use of under- } \\
\text { standable feedback within a reasonable wait time. }\end{array}$ \\
\hline 2 & $\begin{array}{l}\text { Match the Lecturing Platform to the Real World } \\
\text { Information on the platform is shown in a logical order that feels natural to the learner. The lectur- } \\
\text { ing platform uses words, phrases, and concepts that the learners find familiar from their day-to-day }\end{array}$ \\
\hline
\end{tabular}




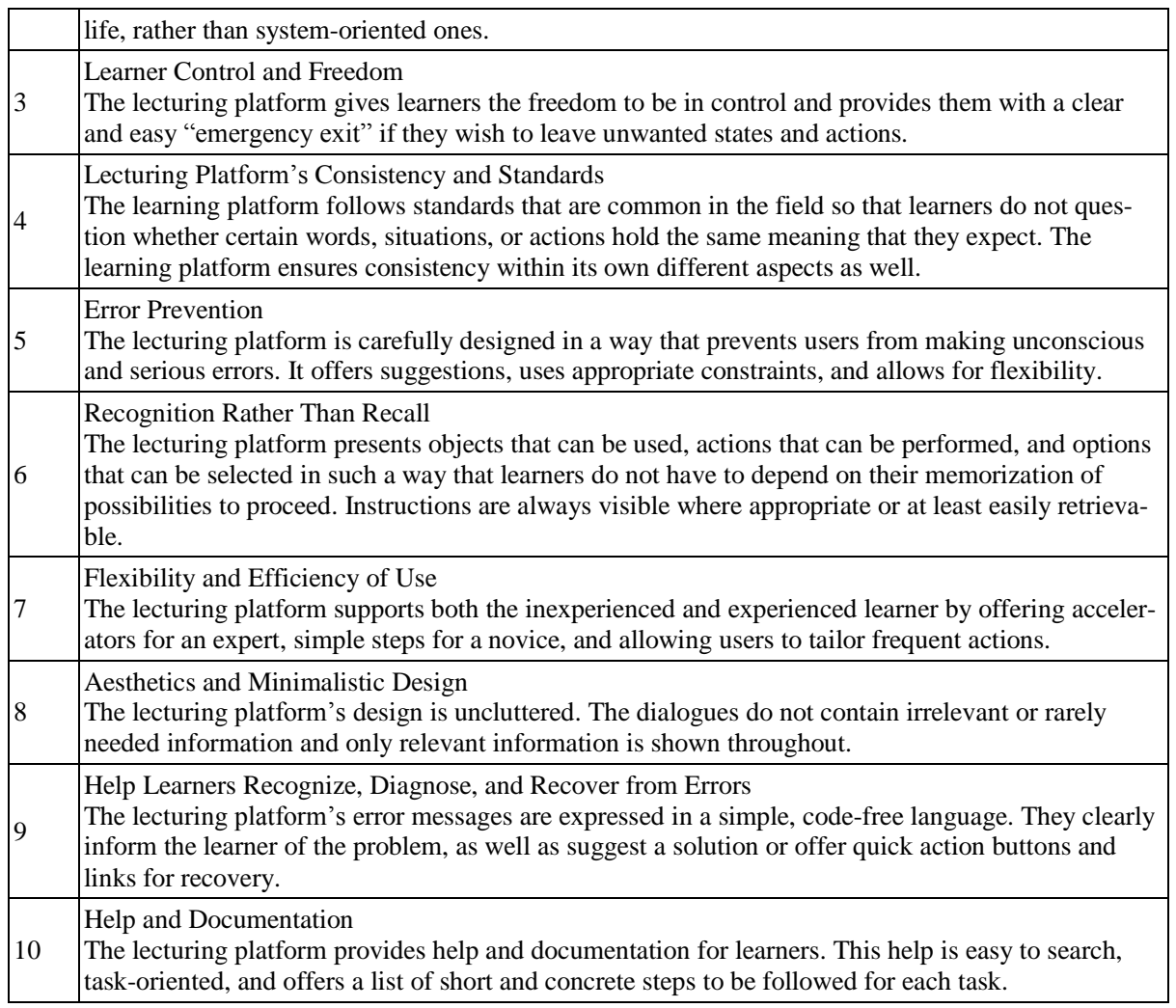

Category 2: User learning style criteria. One area that heuristics of online lecturing have not yet accounted to is a platform's ability to cater to different learning styles. Students process and retain information in a variety of ways [23] [21] [26], which can be influenced by the online lecturing platform's features. Hence, we propose to incorporate the three main VAK learning styles explained earlier. Table 2 illustrates the proposed mapping of usability heuristics to learning styles which can be further extended to cater to additional features in different learning platforms.

Table 2. Category -2- Heuristics - learning style criteria

\begin{tabular}{|l|l|}
\hline Num & \multicolumn{1}{|c|}{ Heuristic Name and Description } \\
\hline 1 & $\begin{array}{l}\text { Support for Visual Learners } \\
\text { The lecturing platform allows learners to grasp information by reading and seeing a figure, images, } \\
\text { and other visualizations. It gives them the opportunity to filter out distracting imagery and noise and } \\
\text { enables them to generate visual instructions out of spoken ones. Files, courses, and other such assets } \\
\text { are visually modifiable, and all visually shared lecture information can be reordered. }\end{array}$ \\
\hline 2 & $\begin{array}{l}\text { Support for Auditory Learners } \\
\text { The lecturing platform allows learners to grasp information by hearing and listening to instructions } \\
\text { and information. It allows them to repeat information out loud, hum, or otherwise utilize their voice } \\
\text { to learn without disturbing others. All auditory parts of a lecture are recordable. }\end{array}$ \\
\hline 3 & $\begin{array}{l}\text { Support for Tactile Learners } \\
\text { The lecturing platform allows learners to grasp information by hands-on doing and interacting. It }\end{array}$ \\
\hline
\end{tabular}


allows them to fidget and move around to remain engaged without disturbing others and it allows them to draw and actively participate on the lecturing board. All such participation can be furthe stored.

\subsection{Phase -2-: Designing evaluation questions mapped to heuristics}

To evaluate the lecturing system against the proposed heuristics and evaluation criteria, several need-finding tools should be utilized to conduct actual evaluation with actual users and compare results with experts' evaluations. The proposed framework allows for a variety of need-finding tools such as interviews and questionnaires that can give a thorough insight into users' experience with the systems under question. In the proposed framework, it is also important to equip the selected need-finding tools with psychometric analysis tests to evaluate learning styles. Moreover, we define criteria for designing good need-finding questions as follows:

- Easy to understand: The questions must use everyday expressions

- Representative of evaluation criteria: The questions must be written in such a way that they represent different aspects of each evaluation criteria.

- Non-Forceful: The questions must not force users to come up with an evaluation if they are not sure.

- Scorable: The questions must be easily and uniformly scoreable and work over a system that leaves no room for misinterpretation.

\subsection{Phase -3-: Defining cognitive style personas}

Personas are concrete representations of the different types of people that the system or service is being designed for. To successfully apply the proposed framework, three major personas need to be targeted to represent different possible users according to their learning styles: one is "Visual Learner", the second is "Tactile Learner", and the third is "Auditory Learner". Based on Interviews and Surveys responses can be categorized into their respective users' personas.

\subsection{Phase -4-: Developing scenarios of use}

In the fourth phase, representative scenarios of use need to be designed to have template "stories" that the researchers can return to when evaluating the interfaces under question, instead of imaging a user doing a task every time. They will be written in an ordered way, using some Personas, and following some guidelines to help the expert evaluator walk through the system and perform relevant tasks as a typical user would do as well as to guide them through user interviews.

\subsection{Phase -5-: Selection of interviewees and questionnaire takers}

Once the evaluation criteria are well defined, the target personas and scenarios of use or clearly identified along with a representative set of evaluation questions, re- 
cruitment of test takes need to be carried carefully. Hence, users doing the surveys or attending interviews need to first undergo psychometric analysis tests to reveal their learning styles as explained in Phase-2- and must be representative of the target user groups.

\subsection{Phase -6-: Conduction of interviews and surveys}

The expert evaluators should oversee and moderate interviews by upholding the role of an objective observer-facilitator as the interviewee fill the survey and answer the questions. Thus, the evaluators should be able to have a broader understanding of the platform's problems from the users' perspective before conducting experts' evaluations of systems under questions on their own. Expert evaluators need as well to walk through the system according to the defined scenarios of use and evaluate the system under questions.

\subsection{Phase -7-: Analysis of missing/unmet users' needs}

In this phase of the evaluation, user needs are analyzed with respect to the interviews conducted, and the inputs of expert evaluators. The output of this phase will be a set of unmet user needs in the systems under question. A compilation of experts' evaluations and users' feedback will guide the identification of unmet users' needs as well as their severity.

\subsection{Phase -8-: Evaluation of the systems}

For evaluating the results of users' responses, in the proposed framework a combination of qualitative and quantitative analyses can be used. Moreover, responses could be grouped by heuristics as well as by users' personas (i.e., learning style). Then scores for each question can be identified/calculated based on the users' ratings which can be analyzed further using appropriate qualitative or quantitative methods.

\section{Techniques}

To apply the proposed framework, we conducted a thorough usability evaluation for Teams and Zoom in the College of Engineering at a local university. Since the start of the COVID-19 pandemic in 2020, the selected university for the study has been using Blackboard and Microsoft Teams as its primary e-Learning platforms. In subsequent sections, we present the detailed design of the usability study according to the proposed framework as well as discuss the results.

\subsection{Phases 1 and 2: Evaluation criteria and questions}

We adopted similar evaluation criteria as illustrated in Table 1 and Table 2 for interaction and cognitive style-related heuristics, respectively. Next, we designed a 
representative set of questionnaire and interview questions mapped to the two sets of heuristics defined earlier in Table 1 and Table 2. Figure 3 presents an exemplary set of questions related to the interaction heuristics and focuses specifically on the "Learner Control and Freedom" Heuristic. Figure 4 presents an exemplary set of questions related to the cognitive style-based heuristics and focuses specifically on the "Support for Auditory Learner" heuristic. Full questionnaires can be requested from the corresponding author via email.

We adopted a Likert scale of 5 points with an additional "I do not know" option will be adopted. A Likert scale is one where a set of 5 or 7 possible answers are offered to the users, ranging from one extreme end to another with a moderate or neutral option in the center. This scale was chosen due to its popularity in measuring opinions and perceptions. Moreover, with this type of scale, we can allow for more granular feedback in place of a binary "Yes" and "No"[27].

In addition, to the heuristics-related survey's an interview's questions, we used a learning style psychometric analysis test provided by Education Planner [28].

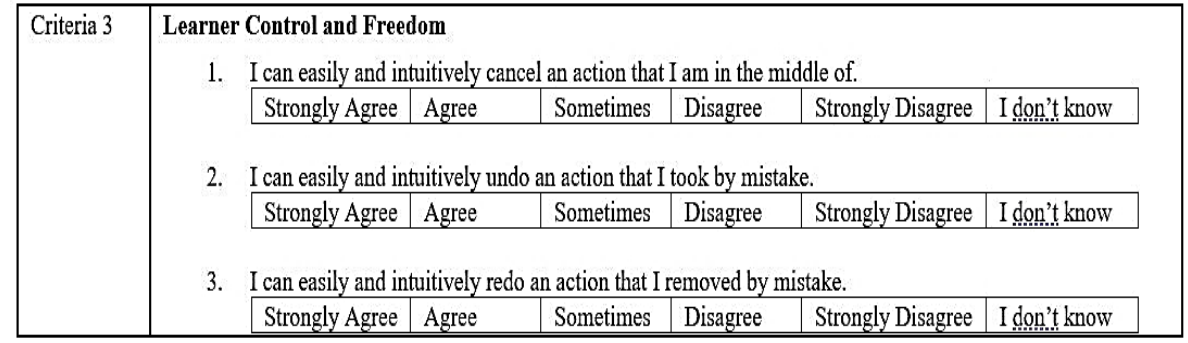

Fig. 3. Interactive usability question sample

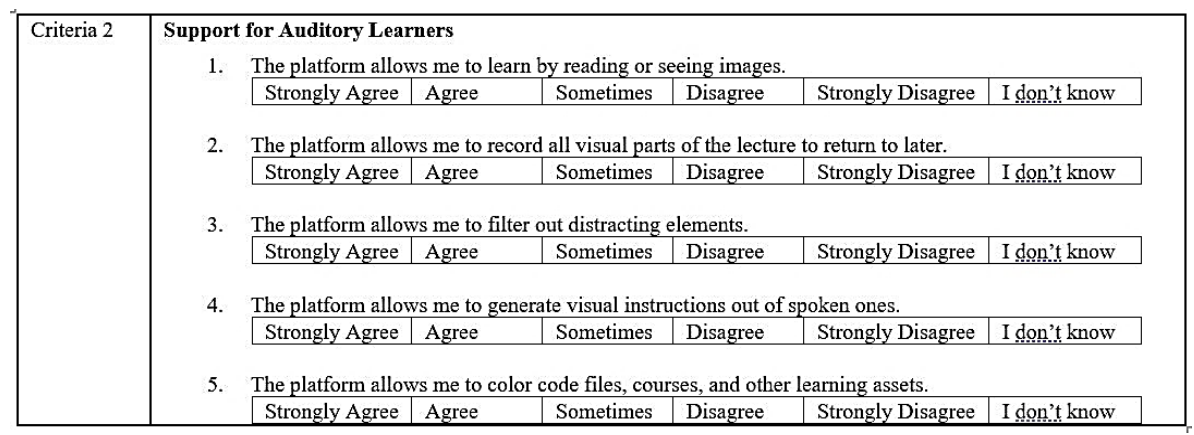

Fig. 4. Learning style accommodation question sample

For the interviews, additional open-ended questions were needed to help get a clear and thorough grasp on the unmet needs that might have not been addressed in the questionnaire's closed-ended questions. Figure 5 presents the interview questions. 


\begin{tabular}{|c|l|}
\hline Num & Interview Question \\
\hline 1 & Could you tell me a little about yourself? \\
\hline 2 & How do you usually spend the lecture time? \\
\hline 3 & Could you describe your typical surrounding environment in a lecture? Are there a lot of distractions? \\
\hline 4 & Could you walk me through a typical scenario of you attending a lecture on the systems? \\
\hline 5 & Was there a time when you wanted to do something in a lecture but could not figure out how to do it, or it was not supported? \\
\hline 6 & Do you feel like the system caters well to your preferences in learning? \\
\hline 7 & What are some problems that you face when using the systems that did not come up in the survey? \\
\hline
\end{tabular}

Fig. 5. Interview question sample

\subsection{Phase 3: Users' personas}

After designing the need-finding questions, three personas for this study were defined to represent different possible users according to their learning styles. The defined personas allow expert evaluators to have a better understanding of the users of the system and facilitate well-informed interviews. Experts can, based on the defined user personas, see the system from the eyes of the target users. The first one is "Visual Learner", the second is "Tactile Learner", and the third is "Auditory Learner". Table 3 illustrates an exemplary persona for a visual learner.

Table 3. Visual learner persona

\begin{tabular}{|c|l|}
\hline Background & $\begin{array}{l}\text { 22 years old. } \\
\text { Information Technology Student. } \\
\text { Likes poetry, writing and painting. } \\
\text { Live with her parents and brother. }\end{array}$ \\
\hline Learning & $\begin{array}{l}\text { Visual Learner. } \\
\text { Likes to learn by watching and highlighting important information. } \\
\text { Visualizes the theory concepts taught in class. } \\
\text { Gets distracted due to the home learning environment. } \\
\text { Likes to make her own notes and study rather than the live classes that she attends. }\end{array}$ \\
\hline Tasks & $\begin{array}{l}\text { Drinks a lot of water before every class. } \\
\text { Ensures that she has notebook, all colors and highlighters in front of her to take } \\
\text { important notes. } \\
\text { Draws and highlights important information in class using colors and highlighters. } \\
\text { Keeps food and snacks beside her, for every class. } \\
\text { More attentive, if the class is very interactive. } \\
\text { Ensures the study table is clean and tidy before every lecture. }\end{array}$ \\
\hline Environ- \\
ment & $\begin{array}{l}\text { Gets distracted while her parents call during the lecture. } \\
\text { However, is very comfortable with the home environment. } \\
\text { Spends more time on computers and is comfortable with it. } \\
\text { Is an intermediate user of computers. }\end{array}$ \\
\hline Quote & • "Learning is very important to me because it gives my life purpose" \\
\hline
\end{tabular}

\subsection{Phase 4: Scenarios of use}

We developed a typical "Morning Lecture" scenario. In the scenario presented in Table 4. , a well-defined set of tasks are defined indicating all possible interactions a user might have with the system under question to attend an online lecture. 
Table 4. Early learning lecture activity - test scenario

\begin{tabular}{|c|c|}
\hline Type & Activity Scenario \\
\hline Title & Early Morning Lecture \\
\hline Overview & $\begin{array}{l}\text { People = Fredrick, an Architecture student. Computer-literate, studies from home. Lives } \\
\text { with his parents. } \\
\text { Activities = Attending a virtual lecture. } \\
\text { Context = Early morning, in the lounge, where his PC is located. } \\
\text { Technology = PC, running MS Teams. }\end{array}$ \\
\hline Rationale & $\begin{array}{l}\text { The activity under study here is attending a lecture. Different actions that must be done } \\
\text { during this activity are described. }\end{array}$ \\
\hline & 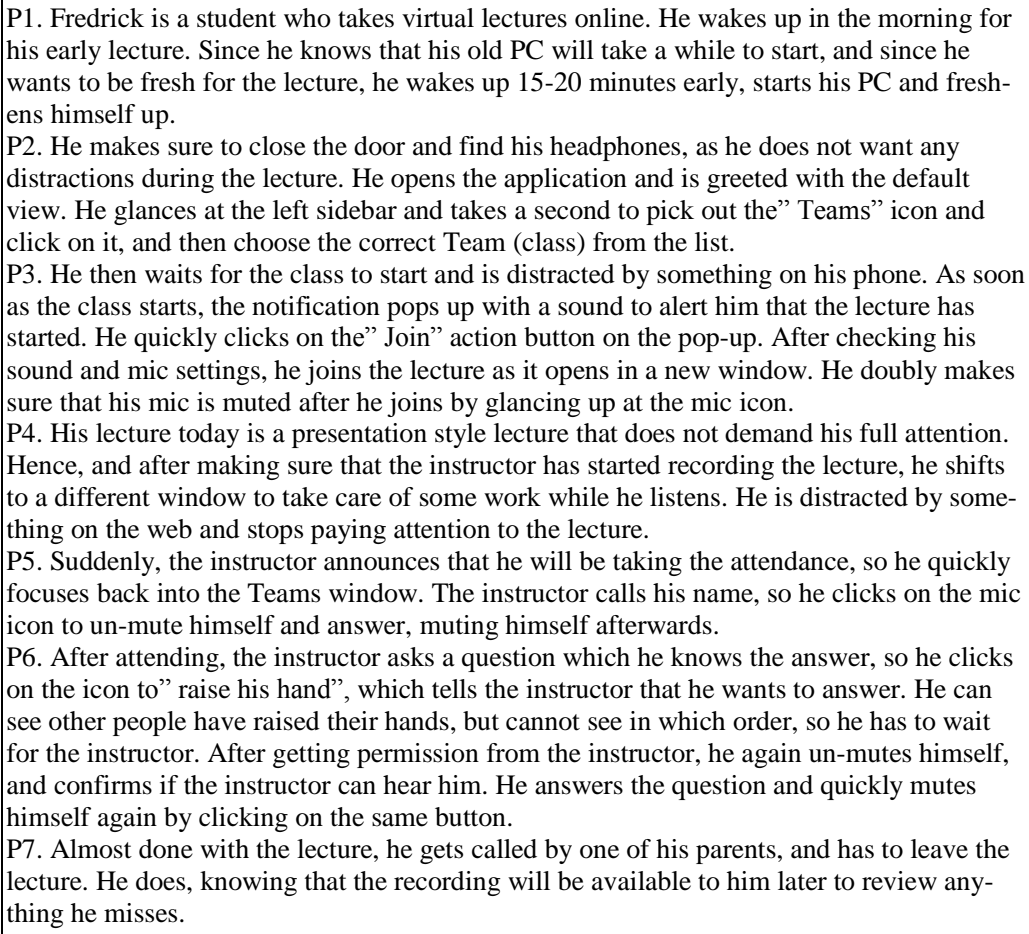 \\
\hline
\end{tabular}

\subsection{Phase 5: Selection of survey and interview taker}

Given that the type of analysis adopted in this study is mainly qualitative, it was more important for us to select representative interviewees belonging to different cognitive styles. This is supported by the argument of Sandelowski [29]. Sandelowski suggests that the samples in qualitative research are usually selected small to support the depth of case-by-case analysis that is essential to this research method. In addition, qualitative samples are for designated use. Hence, we opted for three interviewees so as be able to provide high-texture information related to the research questions. In line with this argument several studies suggested that in purposeful sampling [30], [31]-contrary to the probability sampling used in quantitative research-the "information-rich" case [32] is selected. In fact, latest studies have shown that targeted 
sampling is more effective than random sampling in qualitative research [33] and supports the relevant propositions made by qualitative methodologists for a long time.

Consequently, all the recruited interviewees were tested to discover their learning styles using the quiz provided by Education Planner at [28]. The selected interviewees were ensured to be from different learning styles and genders to guarantee representative results. Additionally, the three interviewees were selected from STEM majors that handle teaching and lecturing in different methods. That is, they were from the Mechanical Engineering, Computer Science, and Architectural Engineering majors. Table 5 summarizes the selection criteria of each interviewee.

Table 5. List of Interviewees

\begin{tabular}{|l|c|c|c|c|c|}
\hline & $\begin{array}{c}\text { Learning } \\
\text { Style }\end{array}$ & Major & Gender & $\begin{array}{c}\text { Courses } \\
\text { Learned Online }\end{array}$ & Computer Skill Level \\
\hline Interviewee 1 & Visual & Computer Science & Female & 11 & Expert \\
\hline Interviewee 2 & Auditory & Mechanical Engineering & Female & 11 & Intermediate \\
\hline Interviewee 3 & Tactile & Architectural Engineering & Male & 8 & Intermediate \\
\hline
\end{tabular}

\subsection{Phases 6, 7, and 8: Conducting the surveys and interviews, need analysis, and final evaluation}

The expert evaluators moderated the surveys and interviews with the selected users as well as evaluated the systems themselves following the predefined scenarios and considering the defined users' personas. In the following sections we discuss results of the evaluation.

\section{Results}

To evaluate the results of the interviews, a qualitative analysis based on the answers received from the users was performed. To answer the two research questions identified in the introduction, an outline of all the unmet needs identified by users in the interviews for both MS Teams and Zoom is summarized in Table 6 factored by user's persona. Next, Table 7 and Table 8, demonstrate the Fleiss's Kappa scores for users' ratings of both systems using the usability evaluation questionnaires against the heuristics defined in the first and second categories respectively is shown in Table 1 and Table 2. Fleiss's Kappa is calculated to measure the agreement among users having different cognitive styles. Low agreement indicates variability in the way those learners interact with the lecturing platforms as well as in the type of usability issues they might face. Subsequently in the discussion section we present a non-parametric statistical evaluation carried on the qualitative results to further address the research questions. 
Table 6. Unmet user needs factored by user persona

\begin{tabular}{|l|l|l|}
\hline \multicolumn{1}{|c|}{ Persona } & \multicolumn{1}{|c|}{ Teams } & \multicolumn{1}{c|}{ Zoom } \\
\hline Visual User & $\begin{array}{l}\text { No feedback for download progress } \\
\text { No retrieval of deleted documents } \\
\text { No warning before enabling the video } \\
\text { Wrong error message }\end{array}$ & $\begin{array}{l}\text { Inconsistent colors and symbols } \\
\text { No warning before enabling the video } \\
\text { Cluttered Menus } \\
\text { No help section }\end{array}$ \\
\hline Auditory User & $\begin{array}{l}\text { No warning message on leaving the call } \\
\text { Chat notifications hides chat box in the } \\
\text { WI } \\
\text { Whiteboard is not recorded }\end{array}$ & $\begin{array}{l}\text { Meetings are not named logically } \\
\text { No help option in the UI } \\
\text { Placement of important buttons makes it easy to } \\
\text { mis-click }\end{array}$ \\
\hline $\begin{array}{l}\text { Tactile } \\
\text { User }\end{array}$ & No hands-on learning support & No warning before enabling the video \\
\hline
\end{tabular}

Table 7. Survey results for category 1 Heuristics (Interaction criteria) - numbers show Fleiss's Kappa interrater agreement score among the three learners (auditory, visual and tactile) for each Heuristic

\begin{tabular}{|l|c|c|}
\hline \multicolumn{1}{|c|}{ Heuristic } & Teams & Zoom \\
\hline Visibility of the Lecturing Platform's Status (5 questions) & 0.3382 & -0.0417 \\
\hline $\begin{array}{l}\text { Match Between the Lecturing Platform and the Real World (4 } \\
\text { Questions) }\end{array}$ & 0 & -0.1707 \\
\hline Learner Control and Freedom (3 Questions) & 0.069 & -0.35 \\
\hline Lecturing Platform's Consistency and Standards (5 Questions) & 0.0426 & 0.0909 \\
\hline Error prevention (3 Questions) & -0.0161 & -0.0385 \\
\hline Recognition rather than Recall (5 Questions) & 0.0769 & -0.1538 \\
\hline Flexibility and Efficiency of use (6 Questions) & 0.2373 & -0.0693 \\
\hline Aesthetics and Minimalist Design (5 Questions) & -0.2931 & -0.3158 \\
\hline $\begin{array}{l}\text { Help Learners Recognize, Diagnose, and Recover from Errors (5 } \\
\text { Questions) }\end{array}$ & 0.2771 & 0.0385 \\
\hline Help and Documentation (4 Questions) & 0 & 0.0943 \\
\hline
\end{tabular}

Table 8. Survey results for category 2 Heuristics (Cognitive style criteria) - numbers show Fleiss's Kappa interrater agreement score among the three learners (auditory, visual and tactile) for each Heuristic

\begin{tabular}{|l|c|c|}
\hline \multicolumn{1}{|c|}{ Heuristic } & Teams & Zoom \\
\hline Support for Visual Learners (5 Questions) & 0.0385 & 0.0407 \\
\hline Support for Auditory Learners (4 Questions) & -0.0667 & -0.5 \\
\hline Support for Tactile Learners (4 Questions) & 0.0204 & 0 \\
\hline
\end{tabular}

\section{Discussion}

As highlighted earlier in the literature review section, Pinchot and Paullet [21] and Newton [22] suggested in their research that students with different learning styles engage in a different way with different representations of the learning content. Therefore, in the first research questions, we aim to further show that learners with 
different cognitive styles interact differently with the lecturing platforms under question, i.e., Teams and Zoom, and accordingly are affected in a different way by the interface design and the usability-related features, which can influence their learning process. At this stage of the research, we aim to prove that variability in terms of interaction modes exists. However, we are not, at this stage, measuring the impact of usability issues on the learning efficacy.

In Tables 7 and 8, we calculated the Fleiss's Kappa [34] interrater agreement scores among the three learners for each heuristic from both categories, introduced earlier in Tables 1 and 2. As shown in Table 7, Kappa scores for category 1 usability heuristics (i.e., Interaction Criteria) indicates fair (0.33) to very poor (-0.29) agreement, and slight (0.09) to very poor (-0.35) agreement among the three learners using Microsoft Teams and Zoom respectively. The low agreement among the three learners relevant to the interaction-related usability heuristics indicates indeed that learners from different cognitive styles adopt different interaction modes with the lecturing platform. The rate and see interaction-usability-related features differently and hence might face different types of usage difficulties as well as incur different interaction challenges that could affect their learning efficacy.

Furthermore, by looking at the Kappa scores reported for category 2 usability heuristics (i.e., Cognitive Style Criteria), which are proposed to be very specific to particular cognitive styles, illustrated in Table 8 , we see even a lower agreement among the learner' rating. As shown in Table 8, Kappa scores for cognitive style-related usability indicate slight $(0.03)$ to very poor $(-0.06)$ agreement, and slight $(0.04)$ to very poor $(-0.50)$ agreement among the three learners using Microsoft Teams and Zoom respectively. These results, do not only show that learners with different learning styles interact differently with the lecturing environment, but also show that the platforms under questions provide low support for learners with different learning styles. These results, indicates that the lecturing platforms under question, cater for the general user group without bearing in its design the variability in users' interaction modes relevant to their cognitive styles which can hinder the learning efficacy. These results answer the first research question.

Further to the analysis of the survey results, we analyzed interviewees responses to the interview questions and grouped the identified issues by user persona as illustrated in Table 6. Following a qualitative analysis of the unmet needs identified by the three learners, we can see that the learners reported different types of usage issues and difficulties in each platform. Moreover, we can see that each user identified some issues that can be associated with his/her cognitive style. For instance, the visual user indicated as the most severe problem on Zoom platform "Inconsistent colors and symbols" which she found distracting. Whereas, the tactile user indicated as the most severe problem on Teams platform "No hands-on learning support". The tactile learner did not bother about the color inconsistency on zoom and the visual learner did not even mention the hands-on support on Teams. These results, further confirm the questionnaire results reported in Tables 7 and 8 , and show that the lecturing platforms under questions were not design to cater for learners/users of different cognitive styles. These results answer the second research question. 


\section{Conclusion}

Upon the COVID-19 global pandemic, video conferencing and communication platforms became a necessity. With the sudden shift to online learning, many institutes had to use video conferencing platforms that were not initially designed for online learning purposes. Even after incorporating many learning-related features, students continued to face challenges in their online lecture. As such, many challenges were faced by students are not only attributed to absence of learning-related features, but also due to usability issues.

In this research we propose a new usability evaluation framework incorporating cognitive styles. The proposed framework allows for an informed selection of online lecturing platforms. In addition, it can guide the design of online lecturing platforms. The proposed framework introduces the first cognitive style-based usability heuristics, which recognize the three key VAT learning styles: visual, auditory, and tactile. The research addressed two main research questions related to how learners of variable cognitive styles interact differently with lecturing platforms as well as how well these lecturing platforms cater for learners with variable cognitive styles.

Results, indicated poor interrater agreement among learners with different cognitive styles when it comes to interaction-related usability features. In addition, a poor agreement was reported when evaluating the usability features related to specific cognitive styles. These results confirm the variability in interaction modes among the learners with variable learning styles. Furthermore, results show that the platforms under question do not actually cater in their design for such variability which can hinder learning efficacy.

Using the proposed framework, designers of lecturing platform can design more usable lecturing platforms suitable for learners with different learning style which can contribute to more learning efficacy.

\section{References}

[1] A. K. Arora and R. Srinivasan, "Impact of pandemic covid-19 on the teaching - learn-ing process: A study of higher education teachers," Prabandhan Indian J. Manag., vol. 13, no. 4, pp. 43-56, 2020. https://doi.org/10.17010/pijom/2020/v13i4/151825

[2] B. Habte, S. Finger, and C. Rosé, "e-learning in engineering through videoconferenc-ing: the case of the addis ababa institute of technology E-Learning in Engineering through Videoconferencing," Int. J. Eng. Pedagog., vol. 3, no. 2, pp. 9-13, Mar. 2013. https://doi.org/1 0.3991/ijep.v3i2.2385

[3] W. Antonelli, "What is Zoom? The popular video-chatting app explained - Business Insider," Nov. 2020.

[4] TrustRadius Research Team, "Microsoft Teams vs Zoom | TrustRadius," 2020.

[5] I. Simonova and M. Bilek, "paper ten years of elearning within the engineering educa-tion in the czech republic ten years of eLearning within the Engineering Education in the Czech Republic,” Int. J. Eng. Pedagog., vol. 2, no. 3, pp. 29-39, Jul. 2012. https://doi.org/10.3991 lijep.v2i3.2095 
[6] L. N. Fewella, L. M. Khodeir, and A. H. Swidan, "Impact of Integrated E-learning: Traditional Approach to Teaching Engineering Perspective Courses," Int. J. Eng. Pedagog., vol. 11, no. 2, pp. 82-101, Mar. 2021. https://doi.org/10.3991/ijep.v11i2.17777

[7] E. Aboagye, J. Yawson, K. A.-S. E. Research, and undefined 2021, "COVID-19 and Elearning: The challenges of students in tertiary institutions," wiserpub.com, Accessed: Jul. 02, 2021. https://doi.org/10.37256/ser.212021422

[8] B. Mehlenbacher et al., "Usable E-Learning: A Conceptual Model for Evaluation and Design," NV Mira Digit. P, vol. 4, pp. 1-10.

[9] S. Ssemugabi and R. De Villiers, "A comparative study of two usability evaluation methods using a web-based e-learning application," ACM Int. Conf. Proceeding Ser., vol. 226, no. January 2007, pp. 132-142, 2007. https://doi.org/10.1145/1292491.1292507

[10] T. C. Reeves et al., "Usability and Instructional Design Heuristics for E-Learning Evaluation.," World Conf. Educ. Multimedia, Hypermedia Telecommun., no. July, pp. 1615$1621,2002$.

[11] İ. Y. Kazu, "The Effect of Learning Styles on Education and Teaching Process," Artic. J. Soc. Sci., 2009. https://doi.org/10.3844/JSSP.2009.85.94

[12] A. Zapalska and D. Brozik, "Learning styles and online education," Campus-Wide Inf. Syst., vol. 23, no. 5, pp. 325-335, Oct. 2006. https://doi.org/10.1108/10650740610714080

[13] H. Ismail, H. Khafaji, H. Fasla, A. R. Younis, and S. Harous, "A cognitive style-based usability evaluation of zoom and teams for online lecturing activities," IEEE Glob. Eng. Educ. Conf. EDUCON, vol. 2021-April, no. April, pp. 1565-1570, 2021. https://doi.org/ 10.1109/EDUCON46332.2021.9454100

[14] E. Rosenzweig, Successful user experience: Strategies and roadmaps. Elsevier, 2015.

[15] J. Nielsen, "How to Conduct a Heuristic Evaluation," Useitcom. pp. 1-11, Nov. 2002, [Online]. Available: http://www.useit.com/papers/heuristic/heuristic_evaluation.html

[16] J. Nielsen and R. Molich, "Heuristic evaluation of user interfaces," in Conference on Human Factors in Computing Systems - Proceedings, 1990, pp. 249-256. https://doi.org/10. $\underline{1145 / 97243.97281}$

[17] C. N. Quinn, "Pragmatic Evaluation: Lessons from Usability," 13th Annu. Conf. Australas. Soc. Comput. Learn. Tert. Educ., p. 437, 1996.

[18] P. Albion, "Heuristic evaluation of educational multimedia: From theory to practice," in 16th Annual Conference of the Australasian Society for Computers in Learning in Tertiary Education, 1999, pp. 9-15.

[19] R. Dunn, "Learning Style: State of the Science," Theory Pract., vol. 23, no. 1, pp. 10-19, Jan. 1984. https://doi.org/10.1080/00405848409543084

[20] A. S. M. Niazy, "What you should know about LEarning Style," Mach. Des., vol. 69, no. 21, p. 55, 1997, [Online]. Available: http://files.eric.ed.gov/fulltext/ED228235.pdf

[21] J. Pinchot and K. Paullet, "Different Keystrokes for Different Folks: Addressing Learning Styles in Online Education," 2014.

[22] P. M. Newton, "The learning styles myth is thriving in higher education," Front. Psy-chol., vol. 6, no. DEC, 2015. https://doi.org/10.3389/fpsyg.2015.01908

[23] A. Y. Kolb and D. A. Kolb, "Learning styles and learning spaces: Enhancing experien-tial learning in higher education," Acad. Manag. Learn. Educ., vol. 4, no. 2, pp. 193-212, 2005. https://doi.org/10.5465/amle.2005.17268566

[24] F. Da and A. Geçer, "Relations between online learning and learning styles," Procedia Soc. Behav. Sci., vol. 1, pp. 862-871, 2009. https://doi.org/10.1016/j.sbspro.2009.01.155

[25] M. Zajac, "Using learning styles to personalize online learning," Campus-Wide Inf. Syst., vol. 26, no. 3, pp. 256-265, Jun. 2009. https://doi.org/10.1108/10650740910967410 
[26] D. M. Mupinga, R. T. Nora, and D. C. Yaw, "The Learning Styles, Expectations, and Needs of Online Students," Coll. Teach., vol. 54, no. 1, pp. 185-189, Jan. 2006. https://doi. org/10.3200/CTCH.54.1.185-189

[27] K. N. Batterton, K. A., \& Hale, "The Likert Scale What It Is and How To Use It.," Phalanx, vol. 50, no. 2, pp. 32-39, 2017, Accessed: Apr. 26, 2021. [Online]. Available: https:// www.jstor.org/stable/26296382

[28] "What's Your Learning Style? 20 Questions." http://www.educationplanner.org/students/ self-assessments/learning-styles-quiz.shtml (accessed Jul. 06, 2021).

[29] M. Sandelowski, "One is the liveliest number: The case orientation of qualitative research,” Res. Nurs. Health, vol. 19, no. 6, pp. 525-529, 1996. https://doi.org/10.1002/(sici) 1098-240x(199612)19:6\%3C525::aid-nur8\%3E3.0.co;2-q

[30] P. Ellis, "Sampling in qualitative research (3)," Wounds UK, vol. 17, no. 1, pp. 128-130, 2021.

[31] M. Byrne, "Sampling for qualitative research.," AORN J., vol. 73, no. 2, 2001. https://doi. org/10.1016/S0001-2092(06)61990-X

[32] J. K. Welch and M. Q. Patton, "Qualitative Evaluation and Research Methods," Mod. Lang. J., vol. 76, no. 4, p. 543, 1992. https://doi.org/10.2307/330063

[33] F. J. Van Rijnsoever, “(I Can't Get No) Saturation: A simulation and guidelines for sample sizes in qualitative research," PLoS One, vol. 12, no. 7, Jul. 2017. https://doi.org/10.1371/ journal.pone.0181689

[34] R. Falotico and P. Quatto, "Fleiss' kappa statistic without paradoxes," Qual. Quant., vol. 49, no. 2, pp. 463-470, Mar. 2015. https://doi.org/10.1007/s11135-014-0003-1

\section{Authors}

Dr. Heba Ismail is an Assistant Professor of Computer Science and Information Technology at Abu Dhabi University, Abu Dhabi, UAE.

Dr. Adel Khelifi is an Associate Professor of Computer Science and Information Technology at Abu Dhabi University, Abu Dhabi, UAE.

Prof. Saad Harous is a Professor of Computer Science at the University of Sharjah, Sharjah, UAE.

Article submitted 2021-07-06. Resubmitted 2021-11-14. Final acceptance 2021-11-14. Final version published as submitted by the authors. 